\title{
A Case Report on Ultra-Sonographic Diagnosis of Free Fluid (Ascites) in a Sun Conure (Aratinga solstitialis) and its Management
}

\author{
D.K. Prabhudev ${ }^{1 *}$, K. Senthilkumar ${ }^{1}$, G.R. Baranidharan ${ }^{2}$, D. Sumathi ${ }^{2}$, \\ M. Palanivelrajan ${ }^{1}$, A. Senthilkumar ${ }^{3}$ and S. Prathaban $^{1}$ \\ ${ }^{1}$ Department of Wildlife Science, ${ }^{2}$ Department of Veterinary Clinical Medicine, Tamil Nadu \\ Veterinary and Animal Sciences University, \\ Madras Veterinary College, Chennai - 600 007, India \\ ${ }^{3}$ Farmers Training Centre, Tamil Nadu Veterinary and Animal Sciences University, \\ Theni-625 531, India \\ *Corresponding author
}

A B S T R A C T

A 3 1 $1 / 2$ month old juvenile Sun Conure (Aratinga solstitialis) was brought to

Keywords

Sun conure,

Ascites, Abdominal ultrasonography

Article Info

Accepted:

16 February 2018

Available Online:

10 March 2018 the Avian and Exotic Pet Unit of Teaching Veterinary Clinical Complex (TVCC), Madras Veterinary College Teaching Hospital (MVCTH) with a history of abdominal swelling, uncoordinated gait, inappetance, lethargy, poor feather quality and diarrhea. Abdominal ultrasonography revealed enlarged liver with rounded borders with free fluid in abdomen. The bird was treated for nonspecific liver disease since the owner did not consent for blood collection and biopsies. Oral amoxicillin @ $50 \mathrm{mg} / \mathrm{kg}$ b.wt. for 7 days, oral frusemide @ $8 \mathrm{mg} / \mathrm{kg}$ b.wt. BID for 10 days, oral multivitamins fortified with essential amino acids @ dose rate of $0.2 \mathrm{ml}$ BID was advised for one month. The bird showed progressive improvement in the fluid reduction and increased appetite during the following visits.

\section{Introduction}

Ascites in psittacine birds is the accumulation of non-inflammatory transudate in one or more of the peritoneal cavities or potential spaces. The Sun Parakeet or Sun Conure (Aratinga solstitialis) is a medium-sized brightly coloured parrot native to northeastern South America where in the ascites syndrome is relatively uncommon in these captive birds. It is one of the endangered birds of South America.

\section{Case history and observation}

A $3 \frac{1}{2}$ month old juvenile Sun Conure was brought to the Avian and Exotic Pet Unit of Teaching Veterinary Clinical Complex 
(TVCC), Madras Veterinary College Teaching Hospital (MVCTH) with a history of abdominal swelling, uncoordinated gait, inappetance, lethargy, poor feather quality and diarrhea.

Upon clinical examination revealed temperature was $107{ }^{\circ} \mathrm{F}$, Heart rate approximately 200 beats/minute, soft abdominal swelling which was pendulous in nature (Fig. 1), uncoordinated gait, lethargy, poor feather quality and dehydration more than 5 per cent.

Ultrasonography did by using Esaote MyLab 20 ultrasound machine with $\mathrm{B}$ mode linear transducer at the frequency of $12.5 \mathrm{MHz}$ in ventro dorsal position. Upon ultrasonography in transverse plane revealed rounded liver borders, homogenous parenchyma of liver and anechoic free fluid below liver and in abdomen (Fig. 2).

Upon B mode/ M mode echocardiography revealed heart rate was 220 beats/ minute, rhythm was normal, no pericardial effusions and normal chambers (Fig. 3).

Upon ultrasonography the case was confirmed as ascites due to non-specific liver disease.

\section{Treatment and Discussion}

The bird was treated for nonspecific liver disease since the owner did not consent for blood collection and biopsies. The affected bird was treated with amoxicillin at the dose rate of $50 \mathrm{mg} / \mathrm{Kg}$. b.wt. orally TID for 7 days to counter primary bacterial infection or secondary bacterial infection during viral diseases. To remove ascites fluid, frusemide at the dose rate of $8 \mathrm{mg} / \mathrm{kg}$ b.wt. given orally BID for 10 days. To counter any vitamin and/or amino acid deficiencies or for regrowth of hepatocytes, multivitamins fortified with essential amino acids at the dose rate of $0.2 \mathrm{ml}$ orally BID was advised for one month. The owner was advised to give balanced diet. Advised to include more carbohydrates in diet as energy source and to reduce more fat containing food sources and also advised to reduce stress to the bird.

The bird showed progressive improvement in the fluid reduction and increased appetite during the following visits and completely recovered after 20 days.

Softer and more fluid enlargements of the abdomen which can become quite pendulant in the perching bird, sometimes without apparent ill effect, may be due to either ascites or rupture of the abdominal muscles. Ascites can be confirmed by very careful paracentesis.

This is carried out in the midline at the most pendulant part of the swelling. The ascites is often due to neoplasia of the liver or gonads. In female birds, a soft abdominal swelling may be due to an enlarged oviduct caused by salpingitis, or an impacted soft-shelled egg, both of which may result in an egg peritonitis. Contrast radiography or the use of ultrasound can help in the differential diagnosis (Brian $\mathrm{H}$. Coles, 2007).

In mynah birds, some other Passeriformes and toucans a degenerative iron storage hepatopathy is often responsible for ascites. The latter leads to nearly no differentiation of the inner organs in the radiograph. These birds are often in respiratory distress, consequently good radiographs of this condition are not easy to obtain (Brian H. Coles, 2007).

In budgerigars (Melopsittacus undulatus) and Neophema spp., Avian Polyoma Virus (APV) infection may cause severe clinical signs and mortalities in susceptible nestlings between 10 and 25 days of age. APV replication occurs in all tissues, including the brain, and affected nestlings may be ataxic or have head tremors. 
Fig.1 Affected bird having abdominal distention

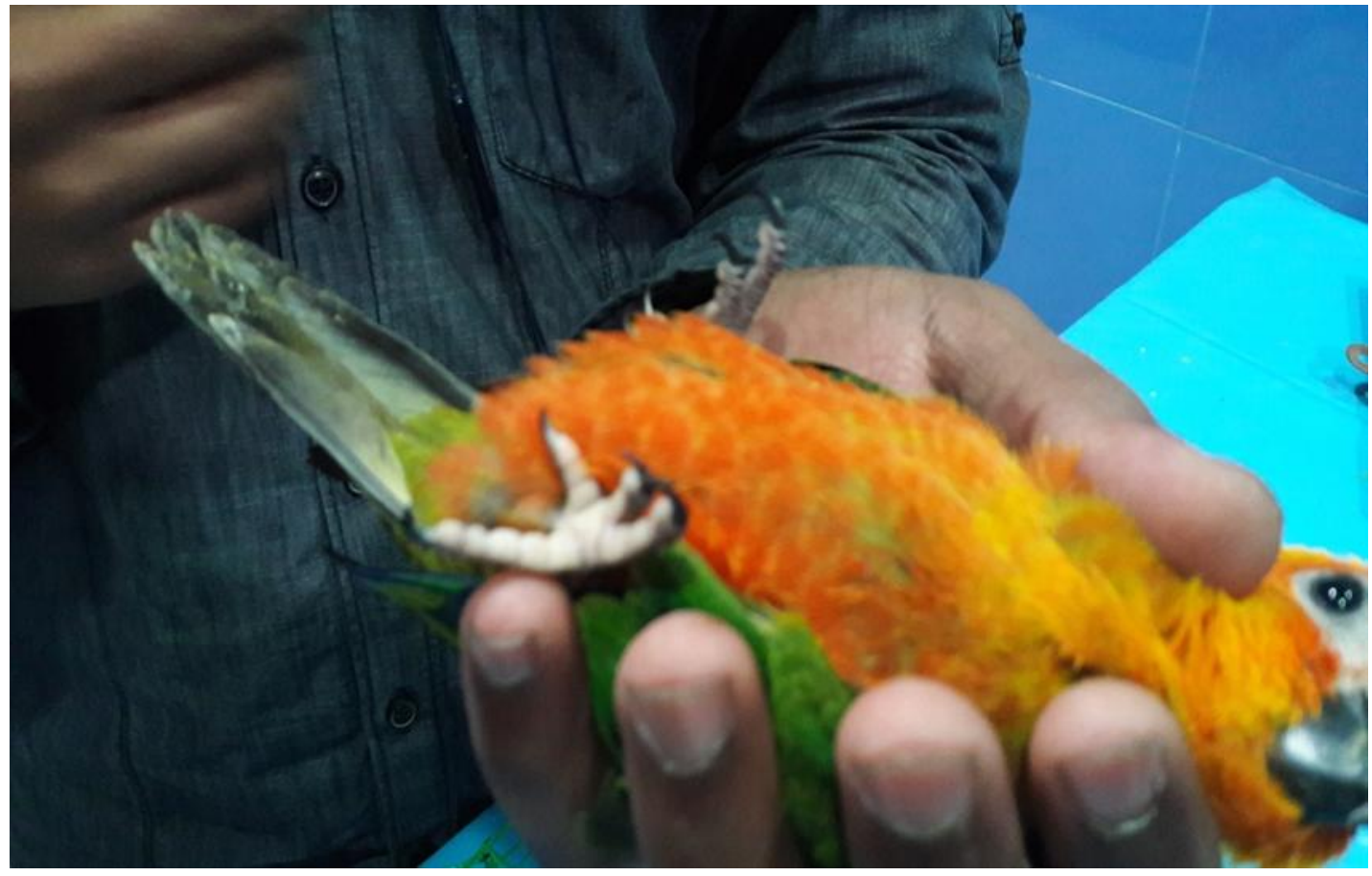

Fig.2 Ultra sonographic image showing free fluid (FF) (ascites) and enlarged liver (L)

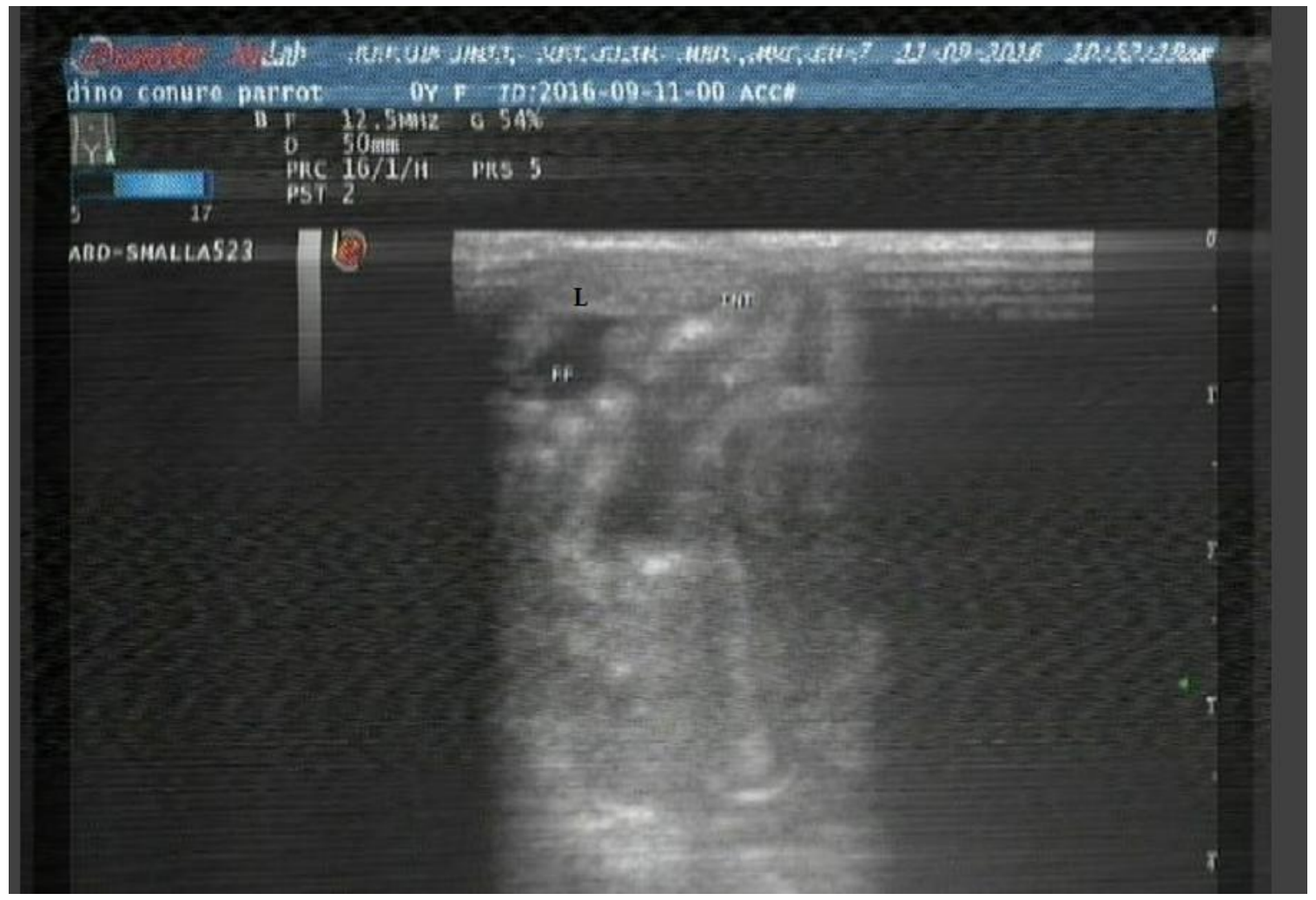


Fig.3 B mode/ M mode Echocardiography

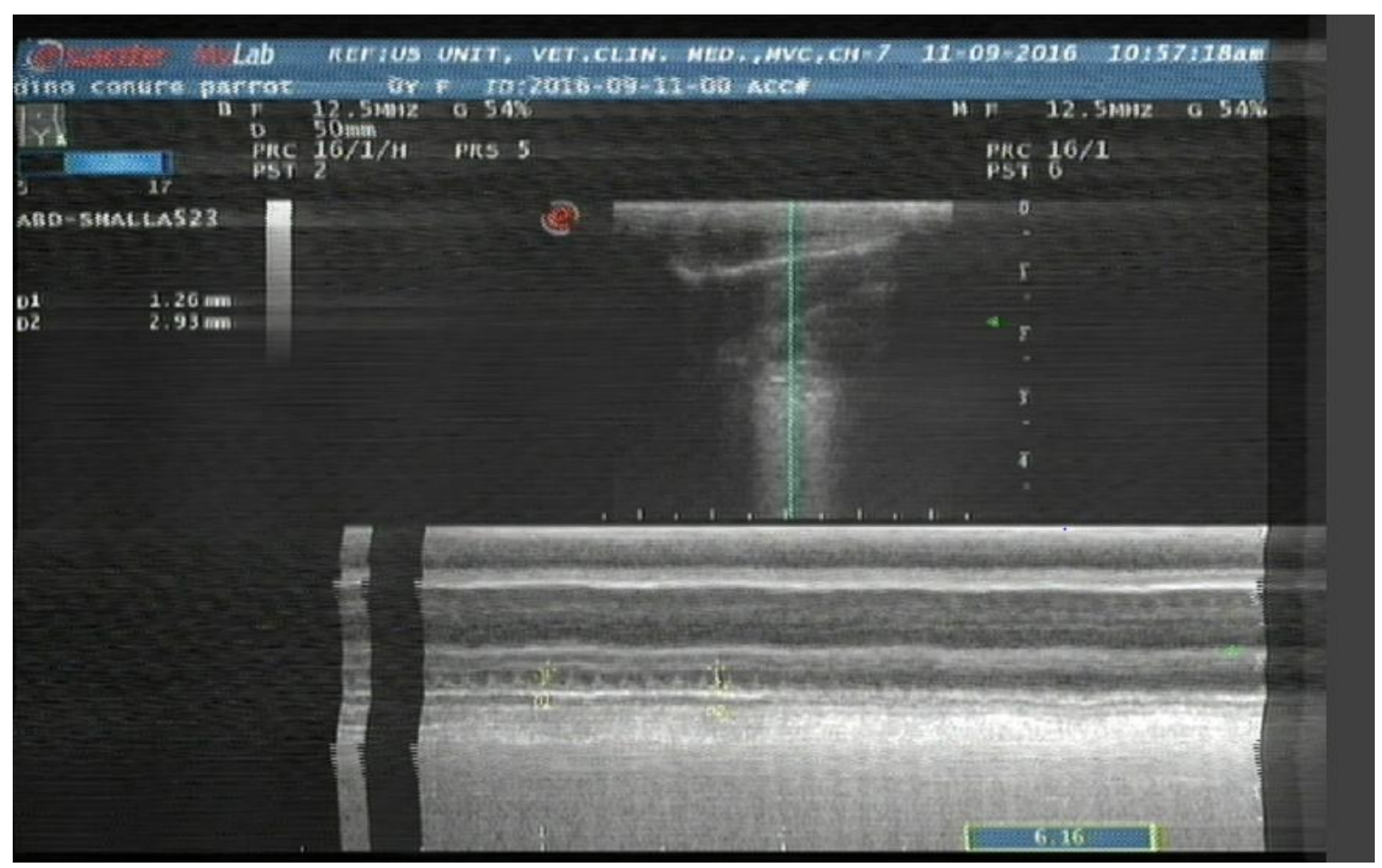

There may be abdominal distension caused by hepatomegaly and ascites; subcutaneous petechiae or ecchymosis or a generalized pallor. The mortality rate in this age group may be $100 \%$, with death occurring rapidly following the development of clinical signs (Eric Miller and Murray Fowler, 2012).

Haemochromatosis is a condition in which excessive amounts of iron are deposited in the liver parenchyma. Birds affected are commonly members of the toucan, toucanette, mynah and starling families. Clinical signs include ascites, dullness, dyspnoea (due to the ascites pressing on the air sacs), abdominal swelling and sudden death. Diagnosis is based on breed predilection and clinical signs, but frequently requires a liver biopsy to assess iron levels (Simon Girling, 2003). Hepatic lipidosis is usually diet related. High fat diets (such as the all-seed diets so beloved of Psittaciformes) and lack of exercise lead to obesity and fat deposition in the liver cells or hepatocytes. Affected birds are often sleek, plump birds, which then become dull and lethargic, and may exhibit signs varying from ascites, to respiratory distress and clotting defects (Simon Girling, 2003).

Avian leukosis/sarcoma virus: this family group of viruses is known to induce a tissue borne leukaemia in Psittaciformes, Galliformes (such as the domestic chicken) and Passeriformes (such as the canary). It destroys the liver and kidneys, which become infiltrated by rapidly dividing lymphocytes. Clinical signs include hepatomegaly and renalomegaly, ascites, respiratory distress, weight loss, green coloured urates, polydipsia and polyuria. There is no treatment (Simon Girling, 2003).

The use of amoxicillin with clavulanic acid @ dose rate of $50 \mathrm{mg} / \mathrm{kg}$ b.wt. BID intramuscularly and frusemide @ 0.15-2 mg/kg b.wt. SID-BID IM, SC or PO as diuretic to reduce ascites are mentioned in the treatment of liver disease in the avian patient (Bob Doneley, 2004).

Amyloidosis is a term used for various diseases that lead to the deposition of proteins in internal 
organs. The proteins are composed of betapleated sheets of non-branching fibrils. Regardless of the cause, amyloid accumulates in the intercellular spaces and impairs the normal access of plasma to hepatocytes. Amyloid deposits can produce varying degrees of hepatomegaly, and extensive accumulations cause the liver to appear pale. In severe cases, affected birds may have clinical signs of either hepatic dysfunction or failure. While hepatic amyloidosis is usually fatal, a case was described in a falcon with hepatomegaly, ascites, leucocytosis, elevated AST (Aspartate Aminotransferase), bile acids and iron levels. Abdominocentesis was performed and a milk thistle derivative was administered for a month. The bird survived for over 3 years (Manfred Hochleithner and Claudia Hochleithner, 2005).

High-risk species for iron storage disease include ramphastids (toucans), mynah birds, starlings and birds of paradise. High amounts of dietary iron seem to be the main cause, although complete pathogenesis is unknown. The mynah was found to have high intestinal absorption and transfer capacity of iron leading to high retention levels. Dyspnea, hepatomegaly, ascites and sudden death are the most common clinical presentations (Manfred Hochleithner and Claudia Hochleithner, 2005).

Ultrasonographically, the liver parenchyma was recognized in all birds and at all frequencies. The characteristic coarse, homogeneous echo texture was similar in appearance to mammalian liver tissue. In the parasagittal plane, both the left and right liver lobes had a triangular shape, were approximately 2 to $3 \mathrm{~cm}$ in depth from caudal to cranial edges, and tapered toward the heart at the midline. Ultrasound techniques in avian species have been described as being impossible or extremely difficult to do because of the small size of most companion birds and the acoustic interference from abdominal air sacs (Cynthia Nordberg and Joanne PaulMurphy, 2000).

\section{Acknowledgement}

The authors are thankful to the Professor and Head, Department of Wildlife Science, Madras Veterinary College, Tamil Nadu Veterinary and Animal Sciences University and the Director of Clinics, Tamil Nadu Veterinary and Animal Sciences University, Chennai for facilities rendered.

\section{References}

Coles, B.H. 2007. Essentials of Avian Medicine and Surgery, $3^{\text {rd }}$ edition. Blackwell publication, U.S.A., pp. 53, 91.

Doneley, B. 2004. Treating liver disease in the avian patient. Semin. Avian. Exot. Pet. 13(1): 8-15.

Girling, S. 2003. Veterinary nursing of exotic pets. Blackwell publication, U.S.A., pp. 66-67, 74-75.

Hochleithner, M. and C. Hochleithner, 2005. Clinical avian medicine- volume 1 . Pp. 441-450.

Miller, R.E. and M. Fowler, 2012. Fowler's Zoo and wild Animal medicine Current therapy (volume 7). Elsevier publication, U.S.A., pp. 301.

Nordberg, C. and J. Paul-Murphy, 2000. Ultrasound examination and guided fineneedle aspiration of the liver in Amazon parrots (Amazona species). J. Avian. Med. Surg. 14(3): 180-184.

\section{How to cite this article:}

Prabhudev, D.K., K. Senthilkumar, G.R. Baranidharan, D. Sumathi, M. Palanivelrajan, A. Senthilkumar and Prathaban, S. 2018. A Case Report on Ultra-Sonographic Diagnosis of Free Fluid (Ascites) in a Sun Conure (Aratinga solstitialis) and Its Management. Int.J.Curr.Microbiol.App.Sci. 7(03): 1969-1973. doi: https://doi.org/10.20546/ijcmas.2018.703.232 